Article

\title{
Apps as Artefacts: Towards a Critical Perspective on Mobile Health and Medical Apps
}

\section{Deborah Lupton}

News \& Media Research Centre, Faculty of Arts \& Design, University of Canberra, Building 9, Bruce ACT 2601, Australia; E-Mail: deborah.lupton@canberra.edu.au; Tel.: +61-(0)-2-6295-0076

External Editor: Bryan R. Hogeveen

Received: 24 September 2014; in revised form: 22 October 2014 / Accepted: 23 October 2014 / Published: 29 October 2014

\begin{abstract}
Although over 100,000 health and medical mobile apps have been placed on the market, few critical social analyses have been yet undertaken of the role of these apps in healthcare, preventive health and health promotion. In this article I present an argument for approaching the study of mobile apps as sociocultural artefacts, focusing specifically on those that have been developed on health and medical topics. This perspective acknowledges that apps are digital objects that are the products of human decision-making, underpinned by tacit assumptions, norms and discourses already circulating in the social and cultural contexts in which they are generated, marketed and used. First, I provide the context, by discussing the gradual digitisation of health and medical information since the advent of the Internet and the emergence of health and medical apps as one of the latest developments. Second, I discuss how a critical perspective may be employed to analyse the social, cultural and political dimensions of health and medical apps. Finally I illustrate how such an approach may be applied by giving a case study of an analysis of the top 10 ranked health and medical apps on the Apple App Store on one day, outlining some major themes and discourses that emerge.
\end{abstract}

Keywords: digital health; mobile apps; health and medicine; critical perspectives; sociology

\section{Introduction}

Mobile software applications (or "apps" as they are commonly known) have become an important element of contemporary digital technology use. Millions of apps designed for smartphones, computer 
tablets and other mobile devices have been published since their first appearance in 2008. Apple announced in mid-2014 that it had over 1.2 million in its App Store catalogue alone and that 75 billion apps had been downloaded by users. The other major app provider, the Google Play store, provides a similar number of apps to consumers [1]. Market research has found that mobile device users spend more time each year on using the apps they have downloaded. One survey of adult smartphone users in the USA found that the average number of hours respondents spent per month on using apps exceeded 30 hours, and that the respondents used an average of 26 apps each [2].

Despite this rapid expansion of a novel method of providing software programs to mobile device users, as yet very few critical social analyses of mobile apps have been published. In this article, as part of a developing research program in critical digital health studies [3-10], I focus attention on one genre of mobile apps: health and medical apps. The vast majority of research studies about this genre of apps have appeared in the medical or public health literature or market research reports. These studies take a primarily instrumental approach, seeking to review the effectiveness of apps or analyse the medical validity or safety of their content using descriptive content analyses. The wider social, cultural and political roles played by health and medical apps as part of contemporary healthcare and public health practice and their contribution to notions of health, illness and embodiment have been little explored thus far.

In this article I seek to achieve three objectives. First, I provide the context, by discussing the gradual digitisation of health and medical information since the advent of the Internet and the emergence of health and medical apps as one of the latest developments. Second, I discuss how a critical perspective may be employed to analyse the social, cultural and political dimensions of health and medical apps. Finally I illustrate how such an approach may be applied by giving a case study of an analysis of the top 10 ranked health and medical apps on the Apple App Store on one day, outlining some major themes and discourses that emerge. In so doing I introduce the concept of the app as sociocultural artefact. This perspective acknowledges that apps are digital objects that are the products of human decision-making, underpinned by tacit assumptions, norms and discourses already circulating in the social and cultural contexts in which they are generated, marketed and used.

\section{Digitising Health and Medical Information}

Health and medical apps are one of the newest developments in a trajectory of the digitising of health and medical information that has occurred over the past quarter century [5]. The emergence of the Internet and mass access to the World Wide Web in the mid-1990s (now often referred to as the "Web 1.0" stage) led to a proliferation of health and medical websites and online discussion groups offering open access to details about illnesses, diseases, health promotion and healthcare. These initial websites were mostly static, infrequently updating their information. They offered little opportunity for people to contribute details of their own experiences, although online discussion groups allowed for some interactions and sharing of information by patients and other interested users.

The digital technologies that have emerged in the past decade (now often referred to collectively as "Web 2.0", or "the social web") have expanded the opportunities for people to access and, in particular, share health and medical information with each other in digital forums. Patients and caregivers can write about their experiences, create and upload images or videos and rate healthcare 
providers and medical treatments using social media platforms and blogs and wireless mobile devices that can connect to the Internet from almost anywhere. In this age of digital "prosumption” (combining production and consumption of Internet content) [11], the ideal of the "digitally engaged patient" (otherwise referred to as the "e-patient") has become dominant. This ideal represents digital technologies as offering patients and lay people the opportunity to 'take control' over their health via contributing to and harnessing online information and engaging in self-monitoring and self-care practices using digital technologies [6,12,13].

\section{The Emergence of Health and Medical Apps}

Sociologists and other social researchers have yet to devote significant attention to the role played by health and medical apps as contributors to these digitised landscapes and ecologies. Yet these apps have proliferated in recent years as part of a constellation of new digital health technologies that include telehealth and telemedicine, digital gaming technologies, digitised medical education and health promotion materials, wearable devices to monitor and measure bodily functions and activities, electronic patient records and booking systems and the use of large digital data sets ("big data") to generate knowledge about healthcare, health behaviours and disease patterns (see $[4,5]$ for an overview). Health and medical apps represent a major element of this market. Tens of thousands of medical and health-related apps for mobile digital devices have already been developed, and more are released onto the market each day. In mid-2014 there were over 100,000 health and medical apps listed in the two major app stores, Apple App Store and Google Play [14].

The health and medical apps that are currently available span a wide range of sophistication of content and markets to which they are designed to appeal. Many are very simple, providing information on a specific medical condition or treatments. Others involve highly detailed anatomical visualisations or incorporate complex algorithms to assist in calculating diagnoses, identifying risks or facilitating health and fitness self-tracking or patient self-care regimes. A variety of apps that are currently on the market are versions of medical training and education directed specifically at medical and other healthcare professionals and students. They provide detailed anatomical information and visuals, digital versions of medical textbooks and dictionaries, training videos and diagrams and drug prescribing information. Apps have been designed for the medical market that can monitor and measure many bodily functions and symptoms in patients as well as work with smartphones to conduct medical tests for diseases and conditions, including add-ons that act as mobile medical devices. Hundreds of apps have also been developed by hospitals and other healthcare providers to market their services and provide opportunities for patients to rate their experiences.

Many more apps are marketed to lay people to provide medical and health information or assist them in self-tracking of their bodily functions and activities. Others are directed at assisting patients to store and access their medical records and treatment regimens and track medical appointments, access medical trials, seek appropriate medical care, engage in patient support networks and share information on their condition with friends and family.

The Internet empires are entering the field of digital health. In mid-2014 Apple announced its new Health app that takes data on health and physical activities from third-party apps and consolidates them into a comprehensive health profile [15]. In September 2014 Apple also announced that its new 
smartwatch, the Apple Watch, would be released early the following year [16]. The Watch will have its own App Store devoted to new apps that are designed especially for its operating system. Among its other functions the Watch will act as a wearable health and fitness-tracking device. As well as allowing users to use third-party apps the Watch incorporates two new apps, simply entitled "Fitness" and "Workout, that will work with the embedded sensors to track users" physical activities and body metrics such as heart-rate.

\section{The Use of Health and Medical Apps}

Evidence suggests that health and medical apps are becoming increasingly used in a variety of contexts. Many writers in the medical and public health literature have drawn attention to the benefits that health and medical apps may offer lay people as well as healthcare practitioners [17-26]. While there is still little research on how people are using health and medical apps, in late 2012 a Pew Research Center survey found that 85 per cent of American adults owned a mobile phone. Fifty-three per cent of these were smartphones, and one fifth of smartphone users had used their phone to download a health-related app. The most popular of these apps were related to monitoring exercise, diet and weight [27]. A more recent market research study found that almost one-third of American smartphone users (equivalent to 46 million people) had used apps from the health and fitness category in January 2014 [28].

It would appear that healthcare practitioners and administrators are also increasingly using apps as part of their professional practice [22,23]. A growing number of medical schools are now offering at least part of their education via apps and require their students to own a tablet computer [29]. In one study that surveyed American doctors, more than two thirds said that they used apps as part of their work. Diagnosis apps were the second most-used category, following those for medication interactions [30]. Another survey of medical students and junior doctors in a UK healthcare region found that over half of both students and junior doctors had medical-related apps on smartphones, with apps for medical education purposes the most popular [31]. Commentators in the medical literature now often refer to "prescribing” apps to patients [32].

On the other hand, however, concern has been raised in the medical and public literature about the quality of apps and the validity of the medical information they contain. Any developer can publish a health or medical app, as long as they conform to the guidelines offered by the app store in which they are seeking to publish (Apple is far more restrictive of the content of the apps it offers than is Google [33]). As a consequence, health and medical apps vary wildly in the accuracy of their content and the extent to which they draw upon credible and reputable sources of information. Some app developers have longstanding reputations in online medical information and training resources and provide information about their medically-qualified editorial team. However many other app developers appear to draw on little or no direct medical expertise when generating the information they present on the apps they offer.

This issue has been recognised as a major concern in the medical literature. Several studies have been published that have identified significant problems with medical accuracy of apps' content [19,34-36]. This research has found that many developers do not nominate specific medical experts in contributing to the content, or are vague in their attribution of authorship, using such terms as “doctors” or “a medical team” [37-41]. Other writers have sought to identify such issues as legal and regulation difficulties and conflict of interest in relation to medical and health apps [23,42-45]. 
As one commentator has observed, medical students are often presented with a list of apps that they are required to use with no discussion of whether or not the developers of these apps discloses conflict of interest. Yet there is nothing to stop a pharmaceutical company developing an app for the medical market that recommends its own products [45].

The relevant regulatory bodies in many countries have not yet established guidelines and regulations for overseeing medical apps. It has been contended that the content of all medical apps should be externally peer-reviewed by medical professionals to ensure quality and safety [34]. Regulatory bodies such as the US Food and Drug Administration (FDA) are struggling to establish the processes by which this should take. In September 2013 the FDA issued draft guidelines for the regulation of health and medical apps [46]. Many apps in these categories do not come under these guidelines' purview, however, as what is considered a "medical device" is currently ambiguous, leading to confusion about exactly which types of apps should be submitted to the FDA for review [47]. Furthermore, these guidelines do not attempt to cover the vast numbers of apps that provide information on medical and health matters, meaning that consumers must exercise their own judgement concerning the validity and accuracy of this information.

\section{Critical Approaches to Health and Medical Apps}

The sociomaterial theoretical perspective on technologies has offered valuable insights into ways of thinking about the relationship between humans and nonhumans in the context of digital health. This perspective has been most commonly articulated in science and technology studies, and in particular, actor network theory. From this approach, technologies participate as material actors in relationships with human actors to configure human-technology assemblages [48]. This approach acknowledges the combination of the material and non-material, the human and the nonhuman, the fleshly and the ideational in ever-changing configurations. It therefore recognises the dynamic nature of people's interactions with technologies in a world in which the digital is increasingly part of everyday lives, social relationships and concepts of subjectivity and embodiment [49]. Several sociologists have drawn upon the sociomaterial approach to theorise medical technologies [50-54]. They argue that via these technologies, specific meanings, concepts and practices are enacted in relation to health, disease, health care, public health, embodiment and selfhood. Medical technologies facilitate modes of knowing the body and disease [51].

Apps are one of the latest forms of medical technologies. From the sociomaterial perspective, mobile apps, like all technologies, are considered to assume certain kinds of capacities, desires and embodiments; they also construct and configure them. Apps may be conceptualised as the products of interplays between the human actors who make decisions about their form, content and use and the affordances offered by digital technologies which delimit the scope within which apps can be developed and used [33,55]. Apps are new digital technology tools, but they are also sociocultural products located within pre-established circuits of discourse and meaning. They are active participants that shape human bodies and selves as part of heterogeneous networks, creating new practices and knowledge. They are therefore generative, a productive form of power [56,57]. Apps may further serve political purposes by championing or supporting vested interests and established forms of dominance and authority. 
The technical affordances of apps structure the ways in which they are used and the meanings that are ascribed to them. The mobility, ease of access and use of apps is a particular feature that differentiates them from earlier sources of health and medical information. Due to their simple format and location on mobile wireless devices, apps can be easily downloaded and carried around for constant reference or updating the user's own information or comments and sharing these with others. The well-known motto of Apple-“"There’s an app for that”- suggests the multi-functional dimensions of apps. Many apps are free or obtainable for a small charge, and they are easily and quickly downloaded (and just as easily removed from a device). Another distinguishing feature is the function of many health and medical apps that connect them to sensor technologies in smartphones or wearable devices that promote detailed and continuous monitoring of bodily functions and behaviours. Unlike older-style websites, such apps are able to facilitate the generation of constant digital data on the user's body that can then be transmitted in real-time to healthcare providers or carers or friends and followers on social media sites.

Apps also provide far more opportunities for lay people to access medical information that was previously only available to healthcare practitioners or students, confined to medical libraries, health and medical training and education course materials or professional associations. While many medical apps are designed expressly for the healthcare practitioner and student audiences, they are freely available for any others to download and consult. Indeed many apps have been developed expressly by medical and public health authorities for the purpose of informing members of the public about medical and health issues, such as infant care, immunisation, weight loss, smoking cessation and many more $[3,4,8,9]$. Whether providing medical information or ways for people to promote their health, apps contribute to public pedagogies on health and medical matters [58]. A further important difference between health and medical apps and previous online technologies is the issues they raise for the security and privacy of the often very personal information that some of these apps generate about their users, given that these data are often uploaded to the developers' platforms supported by cloud computing.

All of these features and affordances of health and medical apps require critical attention and theorising. As sociocultural artefacts and actors in social networks, the content and use of health and medical apps can tell us much about which types of illnesses and health conditions are considered important at a particular moment and what medical or health promotion strategies are privileged to prevent or treat these conditions. Various types of capabilities and responsibilities are produced via medical and health apps. They have significant implications for the practice of medicine, medical authority, the delivery of healthcare and public health work and the doctor-patient relationship. These apps have the potential to shape the ways in which the human body is understood, visualised and treated by healthcare workers and non-professional people alike.

In several recent studies I have conducted on health and medical apps, I have adopted a critical approach to the analysis of these technologies. For example my study of sexuality and reproduction apps designed for people to use for self-tracking and monitoring purposes found that concepts of reproductive and sexual embodiment as they were represented in the apps were strongly gendered, supporting norms and assumptions about male and female sexual and reproductive bodies. Male sexuality was rendered as ideally high-performing and competitive, unrelated to reproduction. In contrast, few apps were designed for women to rank their sexual performance. However nearly all 
reproduction apps were targeted at women, centred on their health and fertility [7]. Another of my current studies that focuses on pregnancy apps identifies the focus on self-responsibilisation via self-monitoring of one's own body and that of the unborn that is evident in the apps' focus. These apps seek to enrol pregnant women by highlighting the ways in which close self-monitoring of their pregnant bodies may avoid posing risks to their unborn as part of a broader ethos of reproductive citizenship that involves many other forms of information and digital devices. Pregnancy apps, however, offer even greater opportunities for women to engage in obsessive self-surveillance because of their capacity to produce detailed data continuously in real-time (including using sensors to monitor the pregnant and unborn bodies, such as maternal and foetal heart-rate) and the function many offer of sharing these data with others on social media networks. Here again gendered norms as well as expectations about "good motherhood" are reproduced in such apps (see also [59]).

\section{Case Study: Top-Ranked Health and Medical Apps in the Apple App Store}

To provide a further example of how social researchers might approach the critical analysis of apps as sociocultural artefacts, I present some analysis of the first 10 health and medical apps that were listed in the charts of most popular apps as they were published on the Apple App Store on a day in September 2014. This involved a total of 40 apps, including both the paid and free apps for both categories, as these are separate lists. The App Store was chosen for this purpose because it is one of the two major providers of apps (with Google Play) and because its daily top app charts provide an easily accessible overview of the currently popular apps by content category. The Apple App Store categorises apps into either the "Health \& Fitness" or the "Medical Category" based on the app developers' nominations of which category their apps are designed for. The top charts are reconfigured each day in response to users' downloading habits. As such, the apps listed in this analysis provide only a "snap-shot" of a particular moment in the top 10 (although some apps may stay in the top 10 lists for several weeks or months if they are very popular).

I examine some of the aspects of app content that may be investigated, including topics, approaches, appeals to authority, use of text and imagery and details provided about the developer. App topics can suggest trends in health and medical regimes, treatments and conditions as well as methods in medical education and training. The ways in which they verbally and visually represent the human body provide insights into contemporary notions of embodiment, health and disease. Examining the words used in the app titles and descriptions on the stores and the images used, including the logo and screenshots employed to illustrate what the app offers potential users, is a way of identifying the tacit assumptions that underpin them and their truth and authority claims. Clicking through to the developers' websites to examine their credentials and the statements that they give about privacy of the data that may be uploaded to their platforms and the terms and conditions of use provides another important source of information concerning the knowledge economy of apps and the digital data that they may generate.

Table 1 provides a list of each app appearing on the top 10 for each of the top charts that were examined. 
Table 1. List of top 10 health and fitness and medical apps on the Apple App Store.

\begin{tabular}{|c|c|c|c|}
\hline Health \& Fitness (paid) & Health \& Fitness (free) & Medical (paid) & Medical (free) \\
\hline 7 Minute Workout & Personal Workout & Essential Anatomy 4 & Gray’s Anatomy Student \\
\hline Body Trainer & Daily Ab Workout & Muscle System Pro III & $\begin{array}{l}\text { Breathing Zone Free- } \\
\text { Relaxing Breathing Exercises }\end{array}$ \\
\hline Healthier—Break Reminder & Relax Melodies & $\begin{array}{l}\text { 3D Human Body Organs } \\
\text { Reference }\end{array}$ & Essential Skeleton 4 \\
\hline $\begin{array}{l}\text { Weight N Watch—Daily } \\
\text { Weight Tracker }\end{array}$ & Sleep Pillow & Anatomy Quiz+ & $\begin{array}{l}\text { Biology and Human Body } \\
\text { Anatomy }\end{array}$ \\
\hline Break Reminder & White Noise Lite & Pocket Anatomy & $\begin{array}{l}\text { Relax with Benjamin DeFoor } \\
\text { —-Sleep \& Hypnosis }\end{array}$ \\
\hline Eye Break & Relax Melodies Seasons & $\begin{array}{l}\text { Gray's Anatomy Premium } \\
\text { Edition }\end{array}$ & MRIcro Viewer \\
\hline Easy Calorie Counter & Music Healing & iMedicalOffice & Plastic Surgery \\
\hline $\begin{array}{l}\text { Simply Being-Mediation for } \\
\text { Relaxation \& Presence }\end{array}$ & Paleo Diet Recipes & Learning USMLE & iSurf Brainview Desktop \\
\hline Brainwave Tuner & FreeBMI & DiabetesPal & MBBS Year II by WAGmob \\
\hline All-in Yoga & $\begin{array}{l}\text { Lose Weight with } \\
\text { Benjamin DeFoor }\end{array}$ & Blood Pressure Diary & Living Lung_Lung Viewer \\
\hline
\end{tabular}

As shown in the table, the top 10 paid apps in the health and fitness category in the Apple App Store were those directed at working out ("7 Minute Workout”, "Body Trainer”), counting calories (Easy Calorie Counter) and controlling body weight ("Weight N Watch—Daily Weight Tracker”), reminding users not to sit for too long at a computer and to exercise their bodies and eyes ("Healthier: Break Reminder", "Eye Break" and "Break Reminder"), meditation and relaxation ("Simply BeingMediation for Relaxation \& Presence”, "Brainwave Tuner”) and yoga (“All-in Yoga”). The top 10 free health and fitness apps again focused on workouts ("Personal Workout" and "Daily Ab Workout"), relaxation and better sleep ("Relax Melodies", "Sleep Pillow”, "White Noise Lite”, "Relax Melodies Seasons", "Music Healing”), diet ("Paleo Diet Recipes”) and weight loss ("FreeBMI” and "Lose Weight with Benjamin DeFoor”).

The list of the top 10 paid medical apps was dominated by human anatomy apps. Six of the top 10 paid apps included detailed anatomical atlases of the human body ("Essential Anatomy 4", "Muscle System Pro III”, “3D Human Body Organs Reference”, “Anatomy Quiz+”, "Pocket Anatomy”, “Gray's Anatomy Premium Edition”). It was evident from the wealth of detail provided in these apps on human anatomy, including images of muscular and skeletal systems and the like, as well as the titles and text of the app descriptions and developers' websites, that these apps were predominantly directed at healthcare practitioners and students rather than lay people. The "iMedicalOffice", an app for electronic health records software, was also designed for healthcare practitioners and institutions, while the "Learning USMLE" was a training app for American medical students seeking to take the medical licensing examination required for practising medicine in that country. However the two remaining apps in the top 10 paid medical app category were designed for patients to monitor and self-manage two chronic health conditions: diabetes ("DiabetesPal”) and high blood pressure ("Blood Pressure Diary”). The "Diabetes Pal” app encourages people with diabetes to record their detailed 
bodily data on the app software and these data are automatically synced to the iCloud. The "Blood Pressure Diary” app also involves users self-monitoring and uploading their bodily data to the app.

The top 10 free medical apps on the Apple App Store were also predominantly directed at medical or healthcare professionals (seven of the 10). There were four human anatomy apps similar to those appearing in the paid medical app chart. Two of the top 10 medical apps were related to medical images. One was for viewing images such as MRIs and CT/CAT scans ("MRIcro Viewer") and the other was designed as a tutor for medical education in brain MRI and neuroanatomy ("iSurf Brainview Desktop"). The list also included the "MBBS Year II by WAGmob” app that the app description nominates as helping second year medical students understand the basics of pharmacology, pharmacy, medicinal chemistry, pathology, genetics and genetic engineering using such techniques as tutorials, quizzes and flashcards. For a more general audience, the chart included a breathing control and relaxation app ("Breathing Zone Free-Relaxing Breathing Exercises”) and another app for relaxation featuring self-hypnosis ("Relax with Benjamin DeFoor-Sleep \& Hypnosis"), as well as an app (in Spanish) designed as a support for patients who were contemplating or had undergone plastic surgery ("PlasticSurgery”).

A constellation of interesting social, cultural and political elements may be discerned from this sample of health and medical apps. These include digital bio-objects; healthism and individualism; claims to authority and commercial interests; and data privacy and security. These are further discussed below.

\subsection{Digital Bio-Objects}

Many of the apps described above engage in visual representations and other forms of providing information on the human body. In the case of the human anatomy and body scan reading apps designed for medical practitioners and students, these representations are highly detailed, producing in-depth digitised atlases of the body that render the body transparent to the gaze by peering at what lies beneath the skin. Self-monitoring apps designed for the use of lay people as part of preventive health or the management of chronic conditions participate in a different form of gaze. As was evident in the apps directed at patients engaging in self-care for diabetes and high blood pressure, many apps encourage users to monitor their bodies closely, generating data on many bodily functions.

Webster [53] uses the term "bio-objects" to describe the assemblages created by new biotechnologies. We might productively view the assemblage that is configured via the interactions of human bodies and apps as a digital bio-object, as are the digital data that this assemblage produces. These digital data assemblages, which have also been referred to as “data doubles" [8,60,61], comprise new forms of patienthood and embodiment when configured via apps. They make visible dimensions of the body that previously were hidden, and expose them to often vast audiences by generating digital quantifiable data about bodily functions and behaviours [8].

Not only, therefore, are traditional forms of representation of the human body used in health and medical apps (such as the anatomical images that feature in the medical apps) but also new forms of digitised embodiment, as are generated using self-monitoring health and medical apps. Unlike the static images of the body used in the human anatomy apps, the data doubles that are thus produced by individuals using these apps are constantly changing assemblages as new data are fed into them. These 
data doubles are representations of the user's own body created by use of the app. The information that they configure on the user serves to shape future actions, thus creating a cybernetic relationship between data double and user [8,9,61]. These data have a liveliness and vitality, a social life of their own $[49,62,63]$ that is facilitated by the app.

\subsection{Healthism and Individualism}

Technologies such as health and medical apps represent the vagaries of human embodiment as amenable to control if sufficient vigilance and self-responsibility are exercised. When behaviours and body functions are digitised as quantifiable data, indicators and concepts of health and fitness become narrow representations of these phenomena. Health and wellbeing become represented by certain numbers that are collected by one's self-tracking device, game app or sensor-embedded smart object $[3,7-9,58,61]$.

The health and fitness concerns addressed by these apps demonstrate that efforts to train one's body, lose weight, avoid sitting for too long but also accomplishing work productivity and achieve relaxation and better sleep are important for many of those who download both paid and free apps. Returning to the top 10 paid health and fitness apps, for example, the "Healthier: Break Reminder" app has the tagline "Work Healthier, rest smartly". The description notes that "Research has shown that prolonged sitting in front of a computer not only damages health, but also decreases productivity. Healthier helps you to tackle both." The app description ends with the call to "Start getting healthier today!” The logo features a silver shield with a stylised red love heart shape inside it, suggesting that the app will protect heart health. The description of the app notes that it periodically reminds the user to take a break from their computer as well as providing "HealthierTips" involving "office-suitable exercises for both eyes and body" in which users can engage when taking a break from sitting at the computer. This app, therefore, supports the notion of the healthy worker as productive worker.

Apps that are directed at influencing health-related behaviours and encouraging patient self-care and voluntary promotion of one's own health may be viewed as contributing to a neoliberal political orientation in which "healthism", or the privileging of health above other priorities $[64,65]$ and taking responsibility for one's own health $[8,9,66]$ are idealised. Such perspectives on health and illness states routinely fail to acknowledge the social determinants of health in their focus on individuals and their management of their health. Digital technologies such as health and medical apps tend to support these individualistic approaches [3,5,7-9,12,58,61]. While some apps may feature the opportunity to people to engage with a community of like-minded individuals who are attempting to achieve the same ends, very few are directed at broader social change or activist politics in the spirit of the new public health $[3,4]$.

Furthermore, the taking up of self-tracking health apps and devices in an ever-growing variety of social domains has led to people being "pushed" or coerced into using such technologies in the interests of other actors and agencies. Health and life insurers are beginning to encourage their customers to use self-tracking devices and apps to collect personal health and fitness data and upload these date to their platforms in the interests of gaining "rewards" or being offered lower premiums. Such uses of apps and the personal data they generate raise pressing questions about potential social and economic discrimination against people who do not wish to participate in these activities or those 
who are identified as not meeting targets for appropriate body weight, good health or physical activity levels [63]. Algorithmic calculations using personal health data may lead to predictive privacy harms [67], where individuals are singled out as being "at risk" from ill health and therefore forced to pay higher insurance premiums or may be refused insurance, credit or employment [68].

\subsection{Claims to Authority and Commercial Interests}

The types of authority that are presented in health and medical apps and their roles as agents in the knowledge economy also require attention. As several writers in the medical and public health literature reviewed above have pointed out, many app descriptions or developer websites fail to acknowledge how the specialised health or medical information that are presented in the apps are generated. The apps assume an authority on health and medical matters that are not always supported by any provided material as evidence of how the content was derived, whether it is regularly updated and so on.

This lack of information was evident in most of the apps I analysed above. The developer of the top-ranked paid medical app, “Essential Anatomy 4”, for example, is the 3D4Medical technology company. On its website the company notes that it "specializes in the development of medical, education and health \& fitness apps for professional reference as well as student and patient education". It is also claimed on the website that the company has achieved over 10 million app downloads worldwide, and is clearly successful in marketing its apps. However the company does not provide much detail about how its medical information is derived, noting only that its apps "have all been medically approved and designed to the highest standard”. The developer of the app directed at educating second year medical students, WAGMobile, is a generalist app development company that provide apps for clients in numerous categories. It does not provide any details of how the content is generated, and indeed offers a disclaimer at the bottom of the app description that notes "Please do not take any action based on the content of this app"; an odd caution given that the material is marketed at accomplishing training for medical students.

Apps contribute to a political environment in which the Internet empires are increasingly exerting a variety of "soft power" in their dominance of the digital knowledge economy [49,69,70]. In the age of big data, the data that are generated by apps are becoming increasingly commercialised. As part of engaging in these acts of prosumption, users' personal data are exploited and transformed into commercial profit by other actors and agencies [10,71]. The data produced from self-tracking apps and devices, patient support and opinion websites and those scraped from social media sites where medical and health topics are discussed, for example, possess great value to pharmaceutical, healthcare and biotechnical companies as well as government agencies and public health enterprises [10]. However it is not always apparent where vested interests lie in the provision of medical information in apps either for lay people or members of the medical profession [10,45,72]. At present there is no way of fully identifying the role that pharmaceutical companies or medical device developers may have played in contributing to the content of apps. 


\subsection{Data Privacy and Security}

The lack of information that is provided in many app descriptions or on the developers' websites means that there is often very little transparency about how users' personal information is used by the developer or other parties to which these data may be sold. This was evident in the self-monitoring of chronic diseases apps that featured in the top 10 paid medical app list. The company that the "Diabetes Pal” app, Lobotomo Software, provides no information on the app description or its website on their privacy policy or terms and conditions of use of the app, despite the fact that the app is collecting several aspects of personal health data and storing these data on a cloud storage platform. This is also the case for the "Blood Pressure Diary" app.

In the wake of the Snowden revelations about the use of app data and other personal digital data use in national security surveillance operations, more attention has been paid to data security and privacy on digital platforms and devices. The extent to which the personal health and medical data information that is collected by apps are used commercially and on-sold to third parties is becoming revealed [73-75]. Several reports recently published by privacy organisations have noted the lack of details offered by many medical and health app developers of what they do with users' personal data [72]. The Global Privacy Enforcement Network in a sweep of over 1000 apps found that 60 per cent raised privacy concerns. Many failed to properly inform users how their personal data were being used or made excessive demands for personal data from users [76].

It appears that developers are beginning to take note of consumers' growing concerns about data privacy and security. A market research report of a survey of more than 2000 health and medical app developers found that data security and standards issues were viewed as barriers to further development of this app market [14]. It is notable that in its latest health and medical-related technologies Apple is taking steps to protect users' privacy by outlining how technology developers may use their HealthKit framework in their App Store guidelines. These note that users are given control over their data by explicitly granting each app permission to read and write data to the HealthKit store. The HealthKit data cannot be saved to iCloud or synced across multiple devices and are kept only on the user's device. App developers are not permitted to use information gained from their apps for targeting users with advertising or similar services or disclose users' data to a third party without express permission from the user. Even if permission is granted, the app developers cannot share information with a third party unless they are also providing a health and fitness service to the user, and app developers cannot sell users' data to third parties. App developers are required to state clearly how they will use their personal data and provide a privacy policy. Apps that provide diagnoses, treatment advice or control hardware designed to diagnose or treat medical conditions that do not provide evidence of regulatory approval will be rejected [77].

\section{Conclusions}

In this article I have begun to outline an agenda for understanding and analysing health and medical apps as sociocultural artefacts that are actors in heterogeneous networks of other actors, both human and nonhuman. By presenting a case study of how a critical social analysis of health and medical apps may be undertaken, the kinds of features evident in such technologies' representations on app stores 
have been identified. Such a brief analysis, however, can only go so far in fully illustrating the symbolic and social nature of health and medical apps. I have only touched on a tiny proportion of the vast array of topics and practices that health and medical apps cover.

Much more research is required from a critical perspective on these technologies. Few in depth studies have as yet been conducted into the ways in which lay people engage with health and medical apps, including non-users or those who take up some apps but then relinquish them shortly afterwards. We know very few details about how health professionals such as medical practitioners, hospital administrators, public health professionals and health promoters are incorporating apps and associated mobile digital technologies into their work practices. Little knowledge is available on the practices and tacit assumptions of app developers and designers and the companies that commission apps. Nor do we know how lay people and healthcare and public health workers might be resisting or subverting these devices or creating their own. Analysis of the circulations, transformations and repurposing of the digital data that are generated by apps requires further attention, as do the topics of personal data security and privacy as the domains in which personal health and medical data are collected and used expand. Detailed social research that is able to elucidate the situated knowledges, meanings and uses of apps offers immense potential for social researchers who are interested in health and medicine and in digital technologies.

\section{Conflicts of Interest}

The author declares no conflict of interest.

\section{References}

1. Perez, S. iTunes App Store Now Has 1.2 Million Apps, Has Seen 75 Billion Downloads To Date. TechCrunch, 2 June 2014. Available online: http://techcrunch.com/2014/06/02/itunes-app-storenow-has-1-2-million-apps-has-seen-75-billion-downloads-to-date/ (accessed on 16 September 2014).

2. Nielsen. Smartphones: So many apps, so much time. Media and Entertainment, 1 July 2014. Available online: http://www.nielsen.com/us/en/insights/news/2014/smartphones-so-many-apps-so-much-time.html (accessed on 20 October 2014).

3. Lupton, D. Digitized health promotion: Risk and personal responsibility for health in the web 2.0 era. In To Fix or to Heal? Davis, J., Gonzalez, A.M., Eds.; New York University Press: New York, NY, USA, 2015, in press.

4. Lupton, D. Health promotion in the digital era: A critical commentary. Health Promot. Int. 2014, doi:10.1093/heapro/dau091.

5. Lupton, D. Critical perspectives on digital health technologies. Sociol. Compass 2014, in press.

6. Lupton, D. The digitally engaged patient: Self-monitoring and self-care in the digital health era. Soc. Theory Health 2013, 11, 256-270.

7. Lupton, D. Quantified sex: A critical analysis of sexual and reproductive self-tracking using apps. Cult. Health Sex. 2014, doi:10.1080/13691058.2014.920528.

8. Lupton, D. M-health and health promotion: The digital cyborg and surveillance society. Soc. Theory Health 2012, 10, 229-244. 
9. Lupton, D. Quantifying the body: Monitoring and measuring health in the age of mhealth technologies. Crit. Public Health 2013, 23, 393-403.

10. Lupton, D. The commodification of patient opinion: The digital patient experience economy in the age of big data. Sociol. Health Illn. 2014, 36, 856-869.

11. Ritzer, G. Prosumption: Evolution, revolution, or eternal return of the same? J. Consum. Cult. 2014, 14, 3-24.

12. Sosnowy, C. Practicing patienthood online: Social media, chronic illness, and lay expertise. Societies 2014, 4, 316-329.

13. Greenhalgh, T.; Procter, R.; Wherton, J.; Sugarhood, P.; Shaw, S. The organising vision for telehealth and telecare: Discourse analysis. BMJ Open 2012, 2, e001574. Available online: http://bmjopen.bmj.com/content/2/4/e001574.long (accessed on 5 March 2014).

14. Jahns, R.-G. The 8 drivers and barriers that will shape the mhealth app market in the next 5 years. Available online: http://mhealtheconomics.com/the-8-drivers-and-barriers-that-will-shape-themhealth-app-market-in-the-next-5-years/ (accessed on 16 September 2014).

15. Apple. Health: An entirely new way to use your health and fitness information. Available online: https://www.apple.com/ios/ios8/health/ (accessed on 22 June 2014).

16. Available online: https://www.apple.com/ios/ios8/health/ (accessed on 22 June 2014).

17. Apple. Watch. Available online: http://www.apple.com/au/watch/?cid=wwa-au-kwg-watch-com (accessed on 17 September 2014).

18. Abroms, L.; Padmanabhan, N.; Thaweethai, L.; Phillips, T. Iphone apps for smoking cessation. Am. J. Prev. Med. 2011, 40, 279-285.

19. Patient Apps for Improved Healthcare: From Novelty to Mainstream; IMS Institute for Healthcare Informatics: Parsipanny, NJ, USA, 2013.

20. Burki, T.K. Cancer apps. Lancet Oncol. 2013, 14, 580-581.

21. Kratzke, C.; Cox, C. Smartphone technology and apps: Rapidly changing health promotion. Int. Electr. J. Health Educ. 2012, 15, 72-82.

22. Muessig, K.E.; Pike, E.C.; Fowler, B.; LeGrand, S.; Parsons, J.T.; Bull, S.S.; Wilson, P.A.; Wohl, D.A.; Hightow-Weidman, L.B. Putting prevention in their pockets: Developing mobile phone-based hiv interventions for black men who have sex with men. AIDS Patient Care STDs 2013, 27, 211-222.

23. Ozdalga, E.; Ozdalga, A.; Ahuja, N. The smartphone in medicine: A review of current and potential use among physicians and students. J. Med. Internet Res. 2012, 14, e128.

24. Lewis, L.T.; Wyatt, C.J. Mhealth and mobile medical apps: A framework to assess risk and promote safer use. J. Med. Internet Res. 2014, 16, e210.

25. Muessig, K.; Pike, E.; Legrand, S.; Hightow-Weidman, L. Mobile phone applications for the care and prevention of hiv and other sexually transmitted diseases: A review. J. Med. Internet Res. 2013, 15, e1. Available online: http://www.jmir.org/2013/1/e1/ (accessed on 22 January 2014).

26. Kamel Boulos, M.; Yang, S. Exergames for health and fitness: The roles of gps and geosocial apps. Int. J. Health Geographics 2013, 12, 18. Available online: http://www.ijhealthgeographics.com/content/12/1/18 (accessed on 26 June 2014).

27. Kamel Boulos, M.; Brewer, A.; Karimkhani, C.; Buller, D.; Dellavalle, R. Mobile medical and health apps: State of the art, concerns, regulatory control and certification. Online J. Public Health 
Informatics 2014, 5, e229. Available online: http://ojphi.org/ojs/index.php/ojphi/article/view/4814 (accessed on 22 July 2014).

28. Fox, S.; Duggan, M. Mobile health 2012. Available online: http://www.pewinternet.org/Reports/ 2012/Mobile-Health.aspx (accessed on 21 December 2012).

29. Nielsen, C. Hacking health: How consumers use smartphones and wearable tech to track their health. Available online: http://www.nielsen.com/us/en/newswire/2014/hacking-health-how-consumersuse-smartphones-and-wearable-tech-to-track-their-health.html (accessed on 16 April 2014).

30. Husain, I. Brown medical school will require medical students to use ipad medical textbooks via inkling. Available online: http://www.imedicalapps.com/2011/06/brown-medical-school-requiremedical-students-ipad-medical-textbooks-inkling/ (accessed on 5 March 2014).

31. Huang, G. Doctors going mobile, but still skeptical of connected health. Available online: http://www.xconomy.com/boston/2014/04/08/doctors-going-mobile-but-still-skeptical-ofconnected-health/ (accessed on 8 April 2014).

32. Payne, K.F.B.; Wharrad, H.; Watts, K. Smartphone and medical related app use among medical students and junior doctors in the United Kingdom (UK): A regional survey. BMC Med. Informat. Decis. Making 2012, 12, 121. Available online: http://www.biomedcentral.com/1472-6947/12/121 (accessed on 1 March 2014).

33. Husain, I. Three free healthcare apps physicians should prescribe to their patients. Available online: http://www.imedicalapps.com/2012/04/free-healthcare-apps-physicians-prescribe-patients/ (accessed on 25 April 2014).

34. Mosemghvdlishvili, L.; Jansz, J. Negotiability of technology and its limitations. Inf. Commun. Soc. 2012, 16, 1596-1618.

35. Buijink, A.W.G.; Visser, B.J.; Marshall, L. Medical apps for smartphones: Lack of evidence undermines quality and safety. Evid. Based Med. 2013, 18, 90-92.

36. Bender, L.J.; Yue, K.R.Y.; To, J.M.; Deacken, L.; Jadad, R.A. A lot of action, but not in the right direction: Systematic review and content analysis of smartphone applications for the prevention, detection, and management of cancer. J. Med. Internet Res. 2013, 15, e287. Available online: http://www.jmir.org/2013/12/e287/ (accessed on 3 February 2014).

37. Wolf, J.; Moreau, J.; Akilov, O.; Patton, T.; English, J.; Ho, J.; Ferris, L. Diagnostic inaccuracy of smartphone applications for melanoma detection. JAMA Dermatol. 2013, 149, 422-426.

38. Hamilton, A.; Brady, R. Medical professional involvement in smartphone 'apps' in dermatology. Br. J. Dermatol. 2012, 167, 220-221.

39. Rosser, B.; Eccleston, C. Smartphone applications for pain management. J. Telemed. Telecare 2011, 17, 308-312.

40. Stevens, D.J.; Jackson, J.A.; Howes, N.; Morgan, J. Obesity surgery smartphone apps: A review. Obes. Surg. 2014, 24, 32-36.

41. O'Neill, S.; Brady, R.R.W. Colorectal smartphone apps: Opportunities and risks. Colorectal Dis. 2012, 14, e530-e534.

42. Wallace, L.S.; Dhingra, L.K. A systematic review of smartphone applications for chronic pain available for download in the united states. J. Opioid Manag. 2014, 10, 63-68.

43. Visvanathan, A.; Hamilton, A.; Brady, R. Smartphone apps in microbiology-Is better regulation required? Clin. Microbiol. Infect. 2012, 18, E218-E220. 
44. Yetisen, A.K.; Martinez-Hurtado, J.; da Cruz Vasconcellos, F.; Simsekler, M.C.E.; Akram, M.S.; Lowe, C. The regulation of mobile medical applications. Lab Chip 2014, 14, 833-840.

45. McCartney, M. How do we know whether medical apps work? Br. Med. J. 2013, doi:10.1136/bmj.f1811.

46. Krieger, W. Medical apps: Public and academic perspectives. Perspect. Biol. Med. 2013, 56, 259-273.

47. Strickland, E. The FDA takes on mobile health apps. Available online: http://spectrum.ieee.org/ biomedical/devices/the-fda-takes-on-mobile-health-apps (accessed on 2 September 2014).

48. McCarthy, M. FDA will not regulate most mobile medical apps. Br. Med. J. 2013, doi:10.1136/bmj.f5841.

49. Latour, B. Reassembling the Social: An Introduction to Actor-Network-Theory; Clarendon: Oxford, UK, 2005.

50. Lupton, D. Digital Sociology; Routledge: London, UK, 2015.

51. Mol, A. The Body Multiple: Ontology in Medical Practice; Duke University Press: Durham, NC, USA, 2002.

52. Mol, A.; Law, J. Embodied action, enacted bodies: The example of hypoglycaemia. Body Soc. 2004, 10, 43-62.

53. Timmermans, S.; Berg, M. The practice of medical technology. Sociol. Health Illn. 2003, 25, 97-114.

54. Webster, A. Introduction: Bio-objects: Exploring the boundaries of life. In Bio-Objects: Life in the 21st Century; Vermeulen, N., Tamminen, S., Webster, A., Eds.; Ashgate: Farnham, UK, 2012; pp. 1-10.

55. Prentice, R. Bodies in Formation: An Ethnography of Anatomy and Surgery Education; Duke University Press: Durham, NC, USA, 2013.

56. Goggin, G. Ubiquitous apps: Politics of openness in global mobile communities. Dig. Creat. 2011, 22, 148-159.

57. Mackenzie, A. The performativity of code: Software and cultures of circulation. Theory Cult. Soc. 2005, 22, 71-92.

58. Lash, S. Power after hegemony: Cultural studies in mutation? Theory Cult. Soc. 2007, 24, 55-78.

59. Rich, E.; Miah, A. Understanding digital health as public pedagogy: A critical framework. Societies 2014, 4, 296-315.

60. Johnson, S. "Maternal devices”, social media and the self-management of pregnancy, mothering and child health. Societies 2014, 4, 330-350.

61. Haggerty, K.; Ericson, R. The surveillant assemblage. Br. J. Sociol. 2000, 51, 605-622.

62. Ruckenstein, M. Visualized and interacted life: Personal analytics and engagements with data doubles. Societies 2014, 4, 68-84.

63. Beer, D. Popular Culture and New Media: The Politics of Circulation; Palgrave Macmillan: Houndmills, UK, 2013.

64. Lupton, D. Self-tracking modes: Reflexive self-monitoring and data practices. Available online: http://ssrn.com/abstract=2483549 (accessed on 8 September 2014).

65. Crawford, R. Healthism and the medicalization of everyday life. Int. J. Health Care Serv. 1980, 10, 365-388. 
66. Greenhalgh, T.; Wessely, S. 'Health for me': A sociocultural analysis of healthism in the middle classes. Br. Med. Bull. 2004, 69, 197-213.

67. Lupton, D. The Imperative of Health: Public Health and the Regulated Body; Sage: London, UK, 1995.

68. Crawford, K.; Schultz, J. Big data and due process: Toward a framework to redress predictive privacy harms. Boston College Law Rev. 2014, 55, 93-128.

69. Andrejevic, M. The big data divide. Int. J. Commun. 2014, 8, 1673-1689. Available online: http://ijoc.org/index.php/ijoc/article/view/2161 (accessed on 31 August 2014).

70. Van Dijck, J. The Culture of Connectivity: A Critical History of Social Media; Oxford University Press: Oxford, UK, 2013.

71. Cheney-Lippold, J. A new algorithmic identity: Soft biopolitics and the modulation of control. Theory Cult. Soc. 2011, 28, 164-181.

72. Till, C. Exercise as labour: Quantified self and the transformation of exercise into labour. Societies 2014, 4, 446-462.

73. Ackerman, L. Mobile Health and Fitness Applications and Information Privacy; Privacy Rights Clearing House: San Diego, CA, USA, 2013.

74. Dredge, S. Yes, those free health apps are sharing your data with other companies. The Guardian, 3 September 2013. Available online: http://www.theguardian.com/technology/appsblog/2013/ sep/03/fitness-health-apps-sharing-data-insurance (accessed on 1 October 2013).

75. McCarthy, M. Experts warn on data security in health and fitness apps. Br. Med. J. 2013, doi:10.1136/bmj.f5600.

76. Barcena, M.B. How Safe is Your Quantified Self? Symantech: Mountain View, CA, USA, 2014.

77. Dwoskin, E. Do your apps respect your privacy? Probably not, new report says. The Wall Street Journal, 11 September 2014. Available online: http://blogs.wsj.com/digits/2014/09/11/do-yourapps-respect-your-privacy-probably-not-a-new-report-says/?mod=rss_Technology (accessed on 12 September 2014).

78. Apple. Healthkit and privacy. Available online: https://developer.apple.com/app-store/review/ guidelines/\#healthkit (accessed on 17 September 2014).

(C) 2014 by the author; licensee MDPI, Basel, Switzerland. This article is an open access article distributed under the terms and conditions of the Creative Commons Attribution license (http://creativecommons.org/licenses/by/4.0/). 